\title{
Leave No Trace ordinances for coastal species management: influences on sea turtle nesting success
}

\author{
Matthew Ware*, Mariana M. P. B. Fuentes \\ Florida State University, Marine Turtle Research, Ecology, and Conservation Group, Department of Earth, Ocean, \\ and Atmospheric Science, Tallahassee, FL 32306, USA
}

\begin{abstract}
Coastal environments provide critical ecosystem services but experience a number of threats including marine debris and abandoned beach equipment. To address this threat, municipalities have begun enacting policy measures such as Leave No Trace ordinances. The impact of these ordinances on coastal species management has not yet been established. To evaluate the effectiveness of Leave No Trace ordinances in coastal species management, sea turtle crawl distribution, nesting success, and the frequency of obstructed crawls pre- and post-ordinance at a loggerhead sea turtle Caretta caretta nesting beach in Alabama, USA, were compared between 3 treatment groups: (1) Gulf Shores and Orange Beach with new Leave No Trace ordinances enacted in 2016, (2) Fort Morgan with no ordinance, and (3) the Bon Secour National Wildlife Refuge (NWR) and Gulf State Park with Leave No Trace ordinances but no resident human population. The ordinance had no significant effect on crawl distribution or nesting success across the study site post-ordinance. However, the frequency of obstructed crawls in populated areas declined by $18.1 \%$ with the ordinance. The presence of a resident population was a more significant driver of obstructed crawls than the ordinance, as the Bon Secour NWR and Gulf State Park had fewer obstructed crawls than either populated treatment. With time and increased compliance, Leave No Trace ordinances may have the potential to improve coastal species management and increase coastal ecosystem services through reduced marine debris entanglement and ingestion, reduced physical damage to the environment, and increased tourism revenue and environmental education.
\end{abstract}

KEY WORDS: Coastal zone management · Marine debris $\cdot$ Leave Only Footprints $\cdot$ Loggerhead marine turtle $\cdot$ Caretta caretta $\cdot$ Gulf of Mexico

\section{INTRODUCTION}

Sandy beaches provide valuable ecosystem services to coastal communities, including storm protection (Ruggiero et al. 2001, Defeo et al. 2009), tourism (Klein et al. 2004, Campbell \& Smith 2006), wildlife viewing (Johnson et al. 1996, Tisdell \& Wilson 2002, 2005, Stewart et al. 2016), and habitat for threatened species (NMFS \& USFWS 2008, Stucker et al. 2010). These services, particularly habitat for threatened species, are being increasingly impacted by coastal

*Corresponding author: mw15w@my.fsu.edu population growth and development (Roberts \& Hawkins 1999, Brown et al. 2008, Defeo et al. 2009, Fuentes et al. 2016), erosion (Fish et al. 2008, Ranasinghe 2016), and sea level rise (Baker et al. 2006, Schlacher et al. 2008, Fuentes et al. 2010, Neumann et al. 2010). With climate-change-associated sea level rise and cyclonic storm intensification, further habitat loss is expected (Emanuel 2005, Fuentes et al. 2011, Murdukhayeva et al. 2013, Bacmeister et al. 2018, Nerem et al. 2018). Efforts to protect coastal development from storm surge and flood damage, such as the

(C) The authors 2020. Open Access under Creative Commons by Attribution Licence. Use, distribution and reproduction are unrestricted. Authors and original publication must be credited. 
construction of seawalls and revetments, are likely to increase with climate change and can exacerbate beach loss through increased erosion and restricted shoreline retreat (Pilkey \& Wright 1988, Phillips \& Jones 2006, Escudero-Castillo et al. 2018, RangelBuitrago et al. 2018).

The availability of optimal habitat for beachdwelling or nesting species such as sea turtles and shorebirds is further reduced by anthropogenic pressures associated with coastal development, including abandoned beach equipment or marine debris, artificial lighting, and human activity (Arianoutsou 1988, Mosier \& Witherington 2002, Weishampel et al. 2016, Oliver de la Esperanza et al. 2017). The introduction of plastics and other debris into the marine environment and its deposition in coastal environments has been increasing rapidly over the past several decades (Hidalgo-Ruz \& Thiel 2013, Blickley et al. 2016, Löhr et al. 2017, Garrison \& Fuentes 2019). Interest in reducing marine debris, and abandoned beach equipment in particular, is growing among both the conservation community and the general public given the breadth of its economic and ecological impacts (Beeharry et al. 2017, Löhr et al. 2017, Owens 2018). These impacts include lost tourism revenue (Blakemore \& Williams 2008, Jang et al. 2014, Krelling et al. 2017), increased coastal zone management costs (de Araújo \& Costa 2006, McIlgorm et al. 2011, Oosterhuis et al. 2014), entanglement and/or starvation of wildlife (Gall \& Thompson 2015, Godoy \& Stockin 2018, Lusher et al. 2018), and physical damage to the environment (Chiappone et al. 2005, Abu-Hilal \& Al-Najjar 2009, Richards \& Beger 2011).

To minimize anthropogenic impacts from human presence on sandy beach ecosystems, municipalities in coastal areas have begun adopting pollution-control measures such as product bans, environmental taxes, and Leave No Trace ordinances (James 2000, Ariza et al. 2008, Oosterhuis et al. 2014, Blickley et al. 2016). In the case of Leave No Trace ordinances, municipalities mandate that residents and visitors remove all beach equipment and disposable items by a specified time or forfeit their equipment and potentially face civil penalties such as fines (City Council of the City of Gulf Shores 2015, City Council of the City of Orange Beach 2015). Portions of beaches in the northern Gulf of Mexico have been protected by city and county Leave No Trace ordinances as early as 2010 (Board of County Commissioners of Santa Rosa County 2010, City Council of the City of Panama City Beach 2012, Bay County Board of County Commissioners 2013, Franklin County Board of Commissioners 2014, Board of Commissioners of
Gulf County 2015, Walton County Board of County Commissioners 2018).

Though Leave No Trace ordinances are most often used for social or economic benefits, they are likely to become increasingly utilized for ecological management as coastal populations increase (Arianoutsou 1988, Schlacher et al. 2008, Oliver de la Esperanza et al. 2017). For example, with respect to sea turtles, the enforcement of these ordinances may improve nesting success and increase the number of postemergent hatchlings reaching the water by removing potential obstructions (Tucker et al. 2005, Fujisaki \& Lamont 2016). Nesting females come onto shore to lay their eggs and may encounter large natural and anthropogenic physical obstructions during nesting (Tucker et al. 2005, 2009, Burkholder \& Slagle 2015). These obstructions may cause them to abandon their nesting attempt and return to the water, become entrapped and die from dehydration, or entangled and drown when returning to the water (Laurance et al. 2008, Witherington et al. 2011, Ikaran 2013, Fujisaki \& Lamont 2016). When obstructions are present on the beach, nests tend to be closer to the shoreline, increasing their risk of tidal inundation or erosion (Laurance et al. 2008, Witherington et al. 2011, Pike et al. 2015, Ware \& Fuentes 2018) or, if having to circumvent obstacles, hatchlings spend more time on the beach, increasing their risk of predation and disorientation (Triessnig et al. 2012, Maurer et al. 2015).

Despite the potential benefits of Leave No Trace ordinances to species that use the coastal environment, the ecological benefits of these ordinances have not yet been demonstrated in these environments. To elucidate these potential benefits, our goal was to determine the influence of Leave No Trace ordinances on sea turtle nesting. This was achieved by determining changes in (1) sea turtle crawl and nest distribution, (2) nesting success, and (3) the frequency of obstructed nesting attempts before and after the implementation of a Leave No Trace ordinance at a loggerhead turtle Caretta caretta nesting beach in the northern Gulf of Mexico.

\section{MATERIALS AND METHODS}

\subsection{Study area}

This study took place along the Gulf of Mexico beaches of Baldwin County, Alabama, USA, stretching from Fort Morgan in the west to the Florida-Alabama state line in the east $\left(30.22716^{\circ} \mathrm{N}, 88.02787^{\circ} \mathrm{W}\right.$ to $\left.30.28021^{\circ} \mathrm{N}, 87.51833^{\circ} \mathrm{W}\right)$. The county beaches were 
divided into 5 subunits: Fort Morgan, the Bon Secour National Wildlife Refuge (BSNWR), Gulf Shores, Gulf State Park, and Orange Beach (Fig. 1).

The cities of Gulf Shores and Orange Beach jointly implemented their Leave No Trace ordinances within their respective city limits effective in 2016 (City Council of the City of Gulf Shores 2015, City Council of the City of Orange Beach 2015). These ordinances prohibit the erection of tents or similar canopy structures on the beach (excluding beach umbrellas) and require all beach equipment without a city permit to be removed from the beach no later than $1 \mathrm{~h}$ after sunset. This beach equipment includes, but is not limited to, chairs, loungers, umbrellas or other shelters, paddle vessels (e.g. kayaks, surfboards), fishing gear and other sports equipment, beach toys, bags, and coolers. As protected areas, the BSNWR and Gulf State Park have Leave No Trace policies in place in addition to no permanent residents. Fort Morgan is unincorporated within Baldwin County, so the Leave No Trace ordinance does not apply in this residential area.

\subsection{Sea turtle monitoring and analysis}

Morning nesting patrols from 1 May through 31 August were conducted daily by US Fish and Wildlife Service personnel and members of the citizen-science, federally permitted sea turtle monitoring group 'Share the Beach' across all Alabama beaches from
2011-2018. During these patrols, all sea turtle activities were documented including crawl result (nest vs. false crawl - female emergences which do not result in the deposition of eggs), date, location including GPS, whether the crawl was obstructed, and distances of the nest or apex of the false crawl to the dune and previous night's high tide line.

A before-after control-impact paired sites (BACIPS) design was used to evaluate the effect of the Leave No Trace ordinance on nesting success and the proportion of obstructed crawls. This design separates natural spatial and temporal effects from those of the intervention by monitoring treatment and control sites both before and after the intervention (Torres et al. 2011, Thiault et al. 2017). Nesting success was defined as the proportion of all adult female sea turtle emergences which resulted in the successful deposition of eggs relative to the total number of emergences. Obstructed crawls were emergences which interacted with a physical object, regardless of whether or not the crawl resulted in a nest.

All crawl data were first separated into pre- and post-ordinance time categories with data from 20112015 listed as 'pre-ordinance' and data from 20162018 as 'post-ordinance'. Within each time category, each beach was then assigned to 1 of 3 groups based on the enforcement of the ordinance and the presence of a resident human population. The Leave No Trace treatment group included the cities of Gulf Shores and Orange Beach. Fort Morgan has a resident population but no ordinance, thus it served as a control for

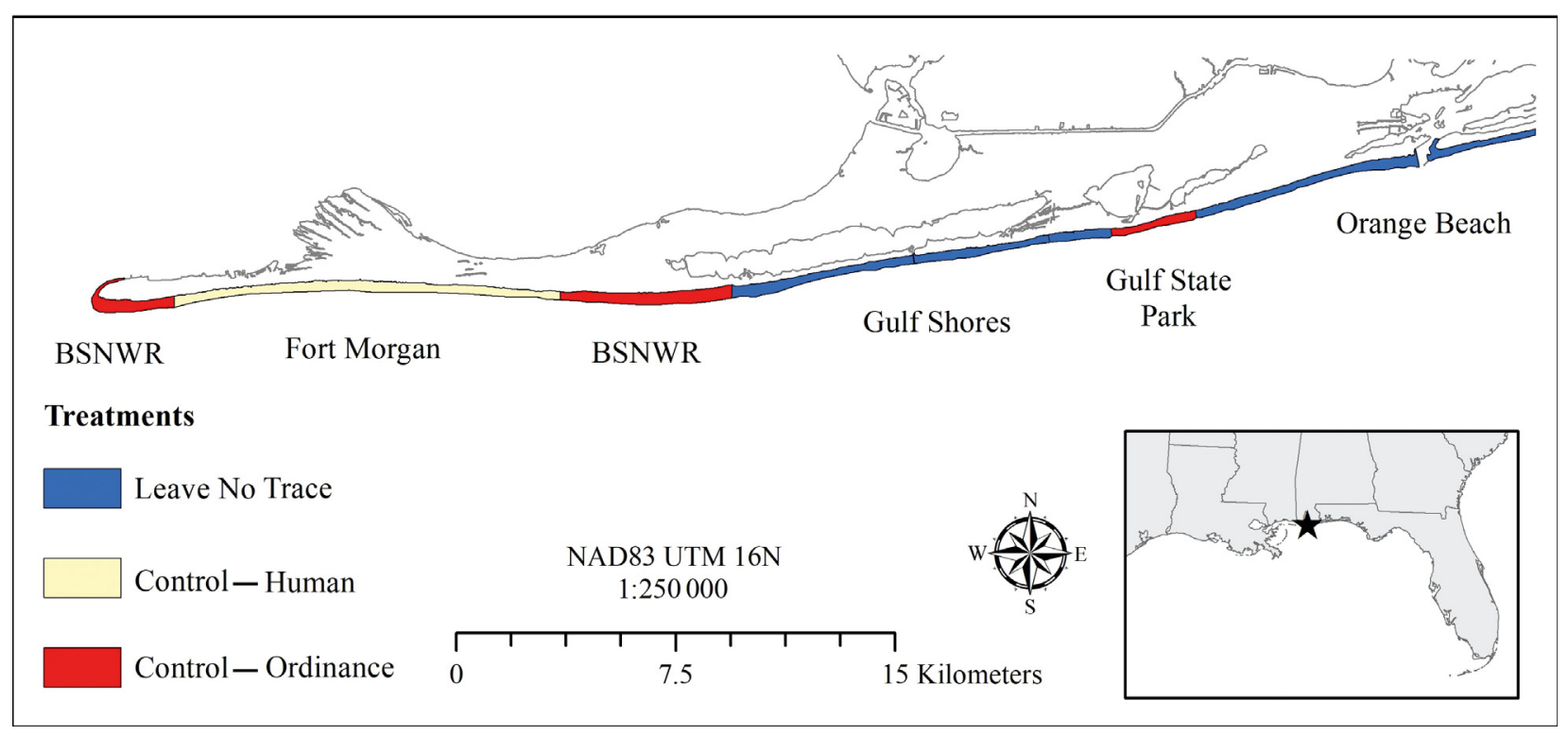

Fig. 1. Baldwin County, Alabama, USA beaches. BSNWR: Bon Secour National Wildlife Refuge. Control—Human: has a resident human population but no ordinance; Control — Ordinance: has an ordinance but no resident human population 
human population. The BSNWR and Gulf State Park served as a control for ordinance as they have Leave No Trace ordinances but no resident population.

Poisson regressions were conducted to evaluate changes in the number of crawls or nests as a function of treatment group, time (pre-/post-ordinance), and the interaction between treatment group and time. Logistic regressions were then conducted to evaluate (1) nesting success as a function of treatment group, time, presence of an obstruction, and distance to the high tide line and (2) the frequency of obstruction as a function of treatment group, time, and distance to the high tide line. In the event a turtle hit multiple objects during her emergence, this event was treated as a single obstructed emergence for the logistic regressions. Each object was treated independently when detailing the prevalence of each type of obstructing object. Distance of the nest or apex of the false crawl to the high tide line was included as it is a commonly recorded metric to assess the risk of inundation exposure to the site and has been shown in previous research to be an important factor in nest site selection (Whitmore \& Dutton 1985, Eckert 1987, Horrocks \& Scott 1991, Kamel \& Mrosovsky 2004, Ávila-Aguilar 2015, Ware et al. 2019). All statistical analyses were performed in R v.3.5.0 (data and $\mathrm{R}$ analyses underlying the manuscript are available from the first author's FigShare site: https:// figshare.com/projects/The_influence_of_Leave_No_ Trace_ordinances_on_coastal_species_management/ 59132).

\section{RESULTS}

\subsection{Sea turtle crawl and nest distribution}

From 2011-2018, there were 1679 crawls across the study area. Of these, 901 were successful nesting attempts resulting in an overall nesting success of $53.7 \%$ (Table S1 in the Supplement at www.int-res. com/articles/suppl/n041p197_supp.pdf). When evaluating the number of crawls as a function of treatment group, time (pre-/post-ordinance), and the interaction of treatment group and time, only treatment group and time were statistically significant (group $\chi^{2} \mathrm{p}=$ 0.045 ; time $\chi^{2} \mathrm{p}=0.001$ ). Though the proportion of crawls in Gulf Shores and Orange Beach increased by $18 \%$ after the ordinance relative to pre-ordinance levels, there was no interaction effect between treatment group and time $\left(\chi^{2} \mathrm{p}=0.537\right)$, indicating that the distribution of crawls was not significantly different after the ordinance was enacted (Fig. 2).
The number of nests were also significantly related to treatment group $\left(\chi^{2} \mathrm{p}=0.043\right)$ and time $\left(\chi^{2} \mathrm{p}=\right.$ $0.005)$ but not the interaction term $\left(\chi^{2} \mathrm{p}=0.790\right)$, indicating no significant change in nest distribution after the ordinance. Though the proportion of nests in Gulf Shores and Orange Beach increased by $12 \%$ after the ordinance relative to pre-ordinance levels, this was not significant. Across Baldwin County, both the mean number of crawls and nests increased after the ordinance by approximately 70 and $50 \%$, respectively, relative to pre-ordinance levels (Figs. 2 \& 3).

\subsection{Sea turtle nesting success}

When evaluating nesting success as a function of treatment group, time, presence of an obstruction, and distance to the high tide line in a logistic regression, only time and distance to the high tide line were significant (Fig. $4 ; \chi^{2} \mathrm{p}<0.0001$ for both time and distance to high tide line, respectively; group $\chi^{2} p=0.375$, obstruction $\chi^{2} p=0.331$ ). There
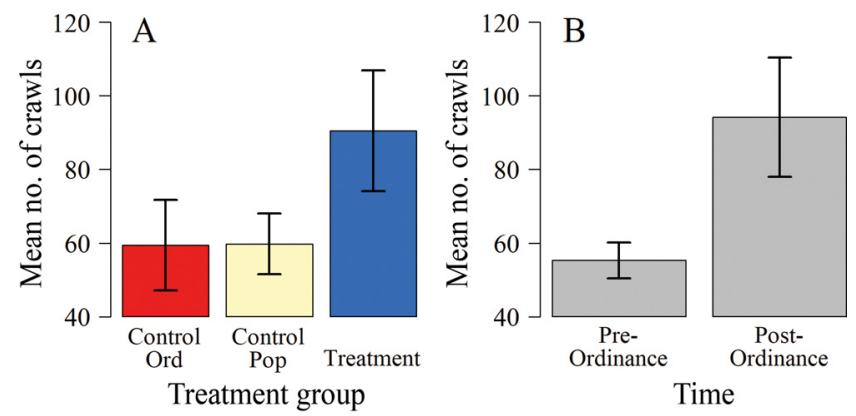

Fig. 2. Mean $( \pm 1 \mathrm{SE})$ number of sea turtle crawls by (A) treatment group and (B) time. Treatment: Gulf Shores and Orange Beach; Control Pop (population): Fort Morgan; Control Ord (ordinance): Bon Secour National Wildlife Refuge and Gulf State Park. The interaction between treatment group and time was not significant
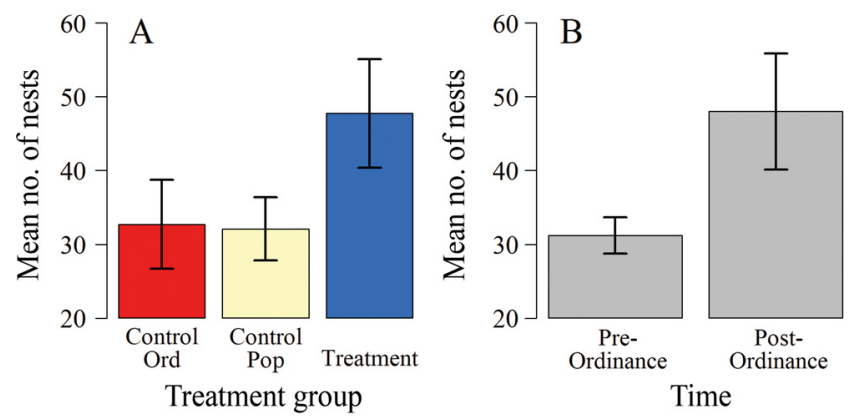

Fig. 3. Mean $( \pm 1 \mathrm{SE})$ number of sea turtle nests by (A) treatment group and (B) time. See Fig. 2 for abbreviations. The interaction between treatment group and time was not significant 
was no interaction effect between treatment group and time $\left(\chi^{2} \mathrm{p}=0.314\right)$.

Before the ordinance went into effect, nesting success was greatest in the BSNWR and Gulf State Park at $58.5 \%$, while after the ordinance it was greatest in Fort Morgan at $54.3 \%$ (Table 1). However, nesting success both before and after the ordinance was not significantly different between treatment groups. Within treatment groups, average nesting success in Gulf Shores and Orange Beach declined by $15.6 \%$, increased in Fort Morgan by $2.1 \%$, and decreased in the BSNWR and Gulf State Park by $11.6 \%$ relative to pre-ordinance levels.

\subsection{Obstructions at nesting beaches}

With respect to the percentage of obstructed crawls as a function of treatment group, time, and distance to the high tide line from 2011-2018, only treatment group and distance to the high tide line were significant (Fig. 5; treatment group $\chi^{2}$ $\mathrm{p}<0.0001$; distance $\chi^{2} \mathrm{p}=0.003$; time $\chi^{2} \mathrm{p}=$ 0.540). There was no interaction effect between treatment group and time $\left(\chi^{2} \mathrm{p}=0.367\right)$.

Before the ordinance went into effect, the percentage of obstructed crawls was lower in the BSNWR and Gulf State Park compared to either Fort Morgan or Gulf Shores and Orange Beach (Table 1). This trend was consistent after the ordinance went into effect as well. Within treatment groups, Fort Morgan had an increase in obstructed crawls of $45.5 \%$ relative to pre-ordinance levels, while Gulf Shores/Orange Beach and BSNWR/ Gulf State Park had decreases of 18.1 and $17.3 \%$ relative to pre-ordinance levels, respectively.

However, the number of obstructing objects increased by $71 \%$ in the 3 yr after the ordinance implementation relative to pre-ordinance levels (Table 2). Tents were the most commonly identified obstruction to sea turtle crawls both before and after the ordinance was initiated, followed by metal beach chairs and wooden loungers. 'Other' objects included items such as kayaks, housing pilings, volleyball nets, and even an old shipwreck (Table 2). Obstructing objects were not identified in reports until 2013-only whether or not the crawl was obstructed. Therefore, the 2011 and 2012 obstructing object data were excluded from this particular level of the analysis. From 2016-2018, roughly $600 \mathrm{t}$ of material were removed from the beaches of Gulf Shores and Orange Beach as part of the Leave
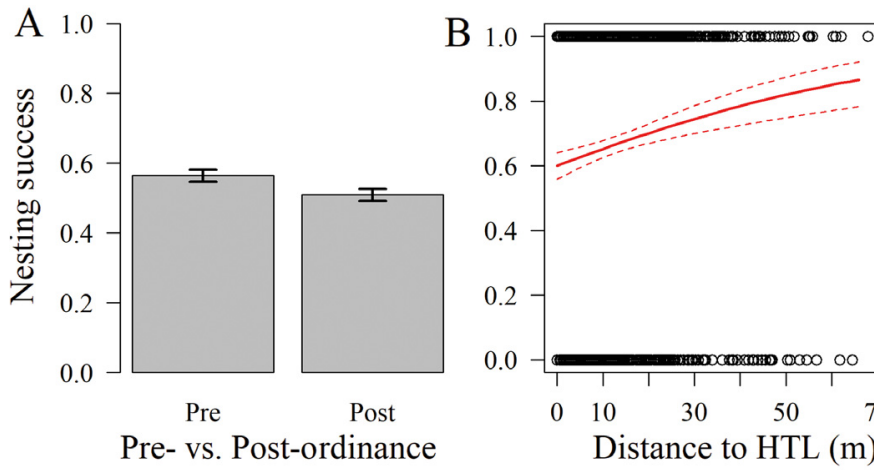

Fig. 4. Sea turtle nesting success (A) by time with all treatment groups aggregated and (B) distance to the high tide line (HTL). Treatment group, presence of an obstruction, and the interaction between treatment group and time were not significant.

Error bars: $\pm 1 \mathrm{SE}$

Table 1. Mean $( \pm \mathrm{SE})$ sea turtle nesting success and percent obstructed crawls by treatment group before (2011-2015) and after (2016-2018) implementation of the Leave No Trace ordinance. Leave No Trace: Gulf Shores and Orange Beach; Control for Ordinance: Bon Secour National Wildlife Refuge and Gulf State Park; Control for Population: Fort Morgan

\begin{tabular}{|lccc|}
\hline & $\begin{array}{c}\text { Leave No } \\
\text { Trace (\%) }\end{array}$ & $\begin{array}{c}\text { Control for } \\
\text { ordinance (\%) }\end{array}$ & $\begin{array}{c}\text { Control for } \\
\text { population (\%) }\end{array}$ \\
\hline Nesting success & & & \\
$\begin{array}{l}\text { Pre-ordinance } \\
\text { Post-ordinance }\end{array}$ & $57.7 \pm 2.7$ & $58.5 \pm 3.2$ & $53.2 \pm 3.0$ \\
Obstructed crawls & $48.7 \pm 2.5$ & $51.7 \pm 3.2$ & $54.3 \pm 3.4$ \\
$\begin{array}{l}\text { Pre-ordinance } \\
\text { Post-ordinance }\end{array}$ & $22.1 \pm 2.3$ & $8.1 \pm 1.8$ & $16.7 \pm 2.3$ \\
& $18.1 \pm 1.9$ & $5.1 \pm 2.9$ & $24.3 \pm 3.0$ \\
\hline
\end{tabular}
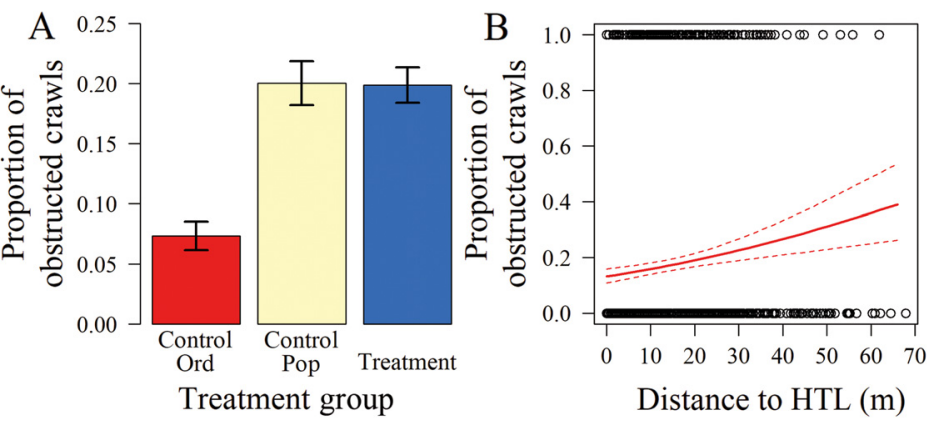

Fig. 5. Proportion of obstructed sea turtle crawls by (A) treatment group and (B) distance to the high tide line (HTL). See Fig. 2 for abbreviations. Time and the interaction between treatment group and time were not significant. Error bars: $\pm 1 \mathrm{SE}$

No Trace ordinance (N. Hand \& N. Woerner pers. comm.). In Orange Beach in 2018 alone, approximately 500 tents, 5000 chairs, and 1200 umbrellas were removed during 5500 collection stops (N. Woerner pers. comm.). 
Table 2. Relative contribution of common beach objects to obstruction of sea turtle crawls pre- and post-ordinance implementation (mean $\pm \mathrm{SE}$ ) across the complete study area. Obstructing objects were not included in nesting reports until 2013 - only whether or not the crawl was obstructed. Therefore, the 2011 and 2012 data are not included in this table

\begin{tabular}{|lcc|}
\hline & $\begin{array}{c}\text { Pre-ordinance }(2013-2015) \\
\mathrm{n}=107 \text { objects }(\%)\end{array}$ & $\begin{array}{c}\text { Post-ordinance }(2016-2018) \\
\mathrm{n}=183 \text { objects }(\%)\end{array}$ \\
\hline Tents & $13.7 \pm 3.2$ & $21.1 \pm 1.7$ \\
Chairs & $12.3 \pm 2.7$ & $17.2 \pm 3.8$ \\
Wooden loungers & $10.6 \pm 5.1$ & $17.5 \pm 4.5$ \\
Umbrellas $_{\text {Toys }}$ & $9.0 \pm 2.4$ & $0.7 \pm 0.7$ \\
Large driftwood $^{\mathrm{a}}$ & $6.7 \pm 0.3$ & $6.1 \pm 2.9$ \\
Holes & $3.9 \pm 2.3$ & $5.5 \pm 1.5$ \\
Sand fencing $^{\mathrm{a}}$ & $3.1 \pm 1.7$ & $10.1 \pm 1.8$ \\
Signage $^{\mathrm{a}}$ & $1.2 \pm 1.2$ & $2.4 \pm 2.4$ \\
Other $^{\text {Unidentified }}$ & $0.0 \pm 0.0$ & $5.1 \pm 2.4$ \\
${ }^{\mathrm{a}}$ Items not included in the Leave No Trace ordinance \\
\multicolumn{2}{|}{} \\
\hline
\end{tabular}

annual variability across the study site and increasing distance of nests from the high tide line.

The statistically insignificant changes in sea turtle crawl and nest distribution reported in the present study is in opposition to Fujisaki \& Lamont (2016), who noted large increases in the number of crawls (89\%) and nests (300\%) in cleared sections of beach on Eglin Air Force Base in northwest Florida. Fujisaki \& Lamont (2016) indicated that most of their debris was large, coarse woody debris (e.g. fallen trees, tree stumps) which covered up to $2 \%$ of the potential nesting area. Clearing this debris along a $1.7 \mathrm{~km}$ stretch of beach resulted in a significant shift of turtle activities from obstructed sections into this cleared section of Eglin Air Force Base. Such a significant shift between cleared and non-cleared sections of beach was not observed in Baldwin County, Alabama. Debris in Baldwin County is largely abandoned beach equipment (which may be easier for sea turtles to navigate around or move out of the way compared to fallen trees or other natural debris) and covered a much smaller fraction of the available nesting beach. In addition, Baldwin County has approximately 10 times the potential nesting area as Eglin Air Force Base. Thus, turtles emerging in Baldwin County have more room to reach suitable nesting habitat, which explains the small effect size noted in the present study. It is possible that Leave No Trace ordinances may result in similar effect sizes to Fujisaki \& Lamont (2016) in locations where abandoned beach equipment covers a percentage of available nesting area equal to or greater than that reported at Eglin Air Force Base. Fujisaki \& Lamont (2016) did not report the frequency of obstructed crawls, so a direct comparison in this respect is not possible.

The presence of a resident human population was a more significant factor in determining the frequency of obstructed crawls than enforcement of the Leave No Trace ordinance, as the BSNWR and Gulf State Park had consistently lower rates of obstruction than the populated beaches both before and after the ordinance implementation. Gulf Shores and Orange Beach observed a decrease in obstructed crawls of $18.1 \%$ relative to pre-ordinance levels, while neighboring, non-ordinance Fort Morgan had a significant (2016). Rather, nesting success was driven by inter- 
relative increase of $45.5 \%$. Tents, beach chairs, and wooden loungers were the most common obstructing objects, accounting for up to $56 \%$ of obstructed crawls. Unfortunately, early reporting during the pre-ordinance time period did not consistently identify the obstructing object, resulting in the large 'unidentified' category during this period (20132015; object identity was never reported in 20112012 and, as such, was removed in this object-identity trend analysis). Combined with increased interest in obstructions post-ordinance, any interpretation of the change in frequency of any particular object should be undertaken with caution.

Despite frequent enforcement of the Leave No Trace ordinance, hundreds of tents and thousands of chairs continue to be left behind overnight for the cities to remove. The direct and indirect effects of this abandoned equipment on coastal species and environments is not well documented in the published literature. Documentation of impacts from this equipment on coastal species and ecosystems (both on land and once it enters nearshore waters carried by storms, wave or tidal action, or attached to marine species) such as restricted mobility, increased energy expenditure, or changes in predation, erosion, or human spatial use need to be reported in order to improve coastal zone management. Entanglement in derelict fishing line, netting, carrying straps for beach chairs, or tent guy lines can restrict adequate feeding and mobility, open wounds susceptible to infection, or result in death from strangulation (Baulch \& Perry 2014, Stelfox et al. 2016, Duncan et al. 2017). The consumption of plastics, fabrics, and other marine debris can lead to starvation from malnutrition or impaction of the gastrointestinal tract (Jacobsen et al. 2010, Di Beneditto \& Arruda Ramos 2014, Duncan et al. 2019). When carried by wind, waves, and currents, derelict equipment can damage nearshore reefs or sensitive coastal vegetation (Chiappone et al. 2005, de Araújo \& Costa 2006, AbuHilal \& Al-Najjar 2009, Richards \& Beger 2011). A reduction in abandoned equipment and improved trash disposal would limit exposure of coastal species to potential entanglement or ingestion hazards and decrease physical damage to marine environments (Bergmann et al. 2015, Gall \& Thompson 2015, Nelms et al. 2016). Structures permitted on the beach by the ordinance (e.g. sand fencing, natural debris, business stands, facilities for public events) may still obstruct sea turtle activities; however, their rates of obstruction in Baldwin County were significantly less than that caused by ordinance-prohibited equipment. In higher concentrations, abandoned beach equipment can pose significant risks to the adults and emergent hatchlings through entrapment, laceration, or drowning (Laurance et al. 2008, Rizkalla \& Savage 2011, Ware \& Fuentes 2018). It is also important to note that enforcement activities themselves, such as nighttime beach cleaning, may deter sea turtle emergence, alter spatial distribution, and/or reduce nest success through increased human activity (Witherington 1992, Jacobson \& Figueroa Lopez 1994, Drobes et al. 2019).

Sea turtle nest site selection is highly variable, and a female turtle may abandon her nesting attempt at any time for reasons beyond obstructions, including human disturbance, artificial lighting, the presence of predators, and unfavorable sand conditions (Hailman \& Elowson 1992, Garmestani et al. 2000, Chen et al. 2007, Kelly et al. 2017, Silva et al. 2017). Nests laid too close to the water are at increased risk of inundation and erosion, while nests closer to the dune risk increased predation of the eggs and emergent hatchlings (Fowler 1979, Mazaris et al. 2009, O'Connor et al. 2017, Ware \& Fuentes 2018, Ware et al. 2019). Significant obstructions on the nesting beach may force sea turtles to nest closer to the water, increasing the risk of nest loss due to wave or tidal action (Rizkalla \& Savage 2011, Witherington et al. 2011).

The environment of the nest site also plays a significant role in sea turtle embryonic development and nest productivity. Factors such as temperature, moisture, gas exchange, salinity, and sediment geology impact the sexual, morphological, and physiological development of the embryo during the roughly 2 mo incubation (Mrosovsky \& Yntema 1980, McGehee 1990, Garmestani et al. 2000, Matsuzawa et al. 2002, Glen et al. 2003, Wallace et al. 2004, Chen et al. 2007). Thus, tents or other canopy structures may alter the incubating environment through shading of the nest (Kamel 2013, Hernandez-Cortes et al. 2018).

Assuming adequate pre-/post-ordinance data and a sufficient nearby control site are available, the BACIPS approach can be applied to other localities with similar ordinances. Tucker et al. (2006) credited the lack of beach equipment-obstructed crawls on Lido Key, Florida to a Leave No Trace ordinance passed the previous year. However, Oliver de la Esperanza et al. (2017) observed that $41 \%$ of the obstructed crawls at Kanzul Beach, Mexico were impacted by beach furniture despite their Leave No Trace ordinance. As these ordinances have been effective conservation measures for more inland ecosystems (Turner 2002), additional investigation is required to clarify the effectiveness of these ordi- 
nances for coastal species management given these mixed results, with particular emphasis on enforcement and the types of obstructions specifically included in the ordinance.

The benefits of Leave No Trace ordinances for coastal species management extend beyond potential changes in sea turtle nesting success. Leave No Trace offers the opportunity for increased tourism, environmental education, and reduced production of marine debris. While it began as a series of educational and land-management principles released by the US Forest Service, US Bureau of Land Management, and US National Park Service in the 1960s to encourage outdoorsmen to leave the environment as undisturbed as possible (Marion \& Reid 2001), Leave No Trace has encouraged a significant increase in protected area visitation, regardless of visitor duration in the area (Taff et al. 2014). This increased visitation at cleaner beaches can increase tourism revenue by millions of dollars, offsetting potential increases in municipal costs for waste removal (de Araújo \& Costa 2006, McIlgorm et al. 2011, Jang et al. 2014, Williams et al. 2016, Krelling et al. 2017). Education about the impacts of human use on sensitive areas can encourage compliance with Leave No Trace principles and reduce human-ecosystem conflicts, including outside of the Leave No Trace area, such as minimized disturbance to wildlife and coastal ecosystems, reduced littering or equipment abandonment resulting in marine debris, and increased participation in environmental cleanups (Zeppel 2008, Lawhon et al. 2013, 2017, Beeharry et al. 2017, Mascovich 2018).

Improvements may not be immediate, as enforcement of, and behavioral changes associated with, a new ordinance require time (Sheavly \& Register 2007, Owens 2018). Visitors and residents in a newly enforced area need time to learn about, and adjust their behavior to comply with, the ordinance. Strategic communications and marketing of the benefits of Leave No Trace ordinances tailored to multiple applications (e.g. threatened species conservation, increased tourism revenue, improved beach aesthetics) may increase adoption of positive environmental behaviors (Ockwell et al. 2009, Kamrowski et al. 2014, Fuentes et al. 2016). With time and compliance, fewer enforcement patrols will be needed, limiting the potential deterrent effect of nighttime human activity on sea turtle nesting, reducing coastal zone management costs, and increasing tourism revenue through cleaner beaches (Jacobson \& Figueroa Lopez 1994, Ballance et al. 2000, de Araújo \& Costa 2006, Jang et al. 2014, Krelling et al. 2017).
Acknowledgements. This work was conducted in collaboration with the United States Fish and Wildlife Service (USFWS) Alabama Field Office, Share the Beach, and the Bon Secour National Wildlife Refuge under USFWS permit numbers TE100012-1 (Share the Beach) and TE206903-01 (Bon Secour National Wildlife Refuge). Significant logistical field support was provided by J. Sablan and several interns, along with the members of Share the Beach, which was greatly appreciated. Funding was provided by USFWS, Alabama Department of Conservation and Natural Resources (grant number F15AC01221), and Florida State University. Academic financial support at Florida State University was generously provided by the Department of Earth, Ocean and Atmospheric Sciences Winchester Scholarship.

\section{LITERATURE CITED}

Abu-Hilal A, Al-Najjar T (2009) Marine litter in coral reef areas along the Jordan Gulf of Aqaba, Red Sea. J Environ Manage 90:1043-1049

* Arianoutsou M (1988) Assessing the impacts of human activities on nesting of loggerhead sea turtles (Caretta caretta L.) on Zákynthos Island, western Greece. Environ Conserv 15:327-334

Ariza E, Jiménez JA, Sardá R (2008) A critical assessment of beach management on the Catalan coast. Ocean Coast Manage 51:141-160

Ávila-Aguilar A (2015) Nest site selection of Lepidochelys olivacea (Testudines: Cheloniidae) in the South Pacific region of Costa Rica. Rev Biol Trop 63:375-381

Bacmeister JT, Reed KA, Hannay C, Lawrence P and others (2018) Projected changes in tropical cyclone activity under future warming scenarios using a high-resolution climate model. Clim Change 146:547-560

Baker JD, Littnan CL, Johnston DW (2006) Potential effects of sea level rise on the terrestrial habitats of endangered and endemic megafauna in the Northwestern Hawaiian Islands. Endang Species Res 2:21-30

Ballance A, Ryan PG, Turpie JK (2000) How much is a clean beach worth? The impact of litter on beach users in the Cape Peninsula, South Africa. S Afr J Sci 96:210-213

Baulch S, Perry C (2014) Evaluating the impacts of marine debris on cetaceans. Mar Pollut Bull 80:210-221

Bay County Board of County Commissioners (2013) BAY Ord. 5-6§5-122: obstructions on the beach and beach access areas prohibited. Bay County Code of Ordinances, Panama City, FL

Beeharry YD, Bekaroo G, Bokhoree C, Phillips MR, Jory N (2017) Sustaining anti-littering behavior within coastal and marine environments: through the macro-micro level lenses. Mar Pollut Bull 119:87-99

Bergmann M, Gutow L, Klages M (eds) (2015) Marine anthropogenic litter. Springer Open, Cham

* Blakemore F, Williams A (2008) British tourists' valuation of a Turkish beach using contingent valuation and travel cost methods. J Coast Res 246:1469-1480

Blickley LC, Currie JJ, Kaufman GD (2016) Trends and drivers of debris accumulation on Maui shorelines: implications for local mitigation strategies. Mar Pollut Bull 105: 292-298

Board of Commissioners of Gulf County (2015) GUL Ord. No. 2015-07: Gulf County Leave No Trace ordinance. Gulf County Code of Ordinances, Port St. Joe, FL

Board of County Commissioners of Santa Rosa County (2010) 
SRO Ord. 14-3(1)§14-54: regulation of use and conduct on the beach and water bodies. Santa Rosa County Code of Ordinances, Milton, FL

Brown AC, Nordstrom KF, McLachlan A, Jackson NL, Sherman DJ (2008) Sandy shores in the near future. In: Polunin NVC (ed) Aquatic ecosystems: trends and global prospects. Cambridge University Press, New York, NY, p 263-280

Burkholder DA, Slagle C (2015) Broward County sea turtle conservation program: 2015 Technical Report. Broward County Commission, Fort Lauderdale, FL

Campbell LM, Smith C (2006) What makes them pay? Values of volunteer tourists working for sea turtle conservation. Environ Manage 38:84-98

* Chen HC, Cheng IJ, Hong E (2007) The influence of the beach environment on the digging success and nest site distribution of the green turtle, Chelonia mydas, on Wanan Island, Penghu Archipelago, Taiwan. J Coast Res 23: 1277-1286

* Chiappone M, Dienes H, Swanson DW, Miller SL (2005) Impacts of lost fishing gear on coral reef sessile invertebrates in the Florida Keys National Marine Sanctuary. Biol Conserv 121:221-230

City Council of the City of Gulf Shores (2015) GFS Ord. 6-1§6-13: 'Leave Only Footprints Program'. Gulf Shores Code of Ordinances, Gulf Shores, AL

City Council of the City of Orange Beach (2015) OGB Ord. 30-6§30-158: beach and dune protection and preservation. Orange Beach Code of Ordinances, Orange Beach, $\mathrm{AL}$

City Council of the City of Panama City Beach (2012) PCB Ord. 7-8§7-122: obstructions on the beach and beach access areas prohibited. Panama City Beach Code of Ordinances, Panama City Beach, FL

de Araújo MCB, Costa MF (2006) Municipal services on tourist beaches: costs and benefits of solid waste collection. J Coast Res 225:1070-1075

* Defeo O, McLachlan A, Schoeman DS, Schlacher TA and others (2009) Threats to sandy beach ecosystems: a review. Estuar Coast Shelf Sci 81:1-12

Di Beneditto APM, Arruda Ramos RM (2014) Marine debris ingestion by coastal dolphins: What drives differences between sympatric species? Mar Pollut Bull 83:298-301

Drobes EM, Ware M, Beckwith VK, Fuentes MMPB (2019) Beach crabbing as a possible hindrance to loggerhead marine turtle nesting success. Mar Turtle Newsl 159:1-4

* Duncan EM, Botterell ZLR, Broderick AC, Galloway TS, Lindeque PK, Nuno A, Godley BJ (2017) A global review of marine turtle entanglement in anthropogenic debris: a baseline for further action. Endang Species Res 34: 431-448

* Duncan EM, Broderick AC, Fuller WJ, Galloway TS and others (2019) Microplastic ingestion ubiquitous in marine turtles. Glob Change Biol 25:744-752

Eckert KL (1987) Environmental unpredictability and leatherback sea turtle (Dermochelys coriacea) nest loss. Herpetologica 43:315-323

Emanuel K (2005) Increasing destructiveness of tropical cyclones over the past 30 years. Nature 436:686-688

* Escudero-Castillo M, Felix-Delgado A, Silva R, MariñoTapia I, Mendoza E (2018) Beach erosion and loss of protection environmental services in Cancun, Mexico. Ocean Coast Manage 156:183-197

Fish MR, Côté IM, Horrocks JA, Mulligan B, Watkinson AR, Jones AP (2008) Construction setback regulations and sea-level rise: mitigating sea turtle nesting beach loss. Ocean Coast Manage 51:330-341

Fowler LE (1979) Hatching success and nest predation in the green sea turtle, Chelonia mydas, at Tortuguero, Costa Rica. Ecology 60:946-955

Franklin County Board of Commissioners (2014) FRK Ord. 57(1)§5-134: Leave No Trace ordinance. Franklin County Code of Ordinances, Apalachicola, FL

Fuentes MMPB, Limpus CJ, Hamann M, Dawson J (2010) Potential impacts of projected sea-level rise on sea turtle rookeries. Aquat Conserv 20:132-139

Fuentes MMPB, Bateman BL, Hamann M (2011) Relationship between tropical cyclones and the distribution of sea turtle nesting grounds. J Biogeogr 38:1886-1896

Fuentes MMPB, Gredzens C, Bateman BL, Boettcher R and others (2016) Conservation hotspots for marine turtle nesting in the United States based on coastal development. Ecol Appl 26:2708-2719

Fujisaki I, Lamont MM (2016) The effects of large beach debris on nesting sea turtles. J Exp Mar Biol Ecol 482: 33-37

Gall SC, Thompson RC (2015) The impact of debris on marine life. Mar Pollut Bull 92:170-179

Garmestani AS, Percival HF, Portier KM, Rice KG (2000) Nest-site selection by the loggerhead sea turtle in Florida's Ten Thousand Islands. J Herpetol 34:504-510

Garrison SR, Fuentes MMPB (2019) Marine debris at nesting grounds used by the Northern Gulf of Mexico loggerhead recovery unit. Mar Pollut Bull 139:59-64

* Glen F, Broderick AC, Godley BJ, Hays GC (2003) Incubation environment affects phenotype of naturally incubated green turtle hatchlings. J Mar Biol Assoc UK 83: 1183-1186

*Godoy DA, Stockin KA (2018) Anthropogenic impacts on green turtles Chelonia mydas in New Zealand. Endang Species Res 37:1-9

Hailman JP, Elowson AM (1992) Ethogram of the nesting female loggerhead (Caretta caretta). Herpetologica 48: 1-30

*Hernandez-Cortes JA, Núñez-Lara E, Cuevas E, GuzmánHernandez V (2018) Natural beach vegetation coverage and type influence the nesting habitat of hawksbill turtles (Eretmochelys imbricata) in Campeche, Mexico. Chelonian Conserv Biol 17:94-103

*Hidalgo-Ruz V, Thiel M (2013) Distribution and abundance of small plastic debris on beaches in the SE Pacific (Chile): a study supported by a citizen science project. Mar Environ Res 87-88:12-18

Horrocks JA, Scott NM (1991) Nest site location and nest success in the hawksbill turtle Eretmochelys imbricata in Barbados, West Indies. Mar Ecol Prog Ser 69:1-8

Ikaran M (2013) Habitat alteration and mortality of adult leatherback turtles in Gabon, Central Africa. Munibe Monogr Nat Ser 1:61-64

Jacobsen JK, Massey L, Gulland F (2010) Fatal ingestion of floating net debris by two sperm whales (Physeter macrocephalus). Mar Pollut Bull 60:765-767

Jacobson SK, Figueroa Lopez A (1994) Biological impacts of ecotourism: tourists and nesting turtles in Tortuguero National Park, Costa Rica. Wildl Soc Bull 22:414-419

James RJ (2000) From beaches to beach environments: linking the ecology, human-use and management of beaches in Australia. Ocean Coast Manage 43:495-514

Jang YC, Hong S, Lee J, Lee MJ, Shim WJ (2014) Estimation of lost tourism revenue in Geoje Island from the 2011 
marine debris pollution event in South Korea. Mar Pollut Bull 81:49-54

Johnson SA, Bjorndal KA, Bolten AB (1996) Effects of organized turtle watches on loggerhead (Caretta caretta) nesting behavior and hatchling production in Florida. Conserv Biol 10:570-577

Kamel SJ (2013) Vegetation cover predicts temperature in nests of the hawksbill sea turtle: implications for beach management and offspring sex ratios. Endang Species Res 20:41-48

Kamel SJ, Mrosovsky N (2004) Nest site selection in leatherbacks, Dermochelys coriacea: individual patterns and their consequences. Anim Behav 68:357-366

Kamrowski RL, Sutton SG, Tobin RC, Hamann M (2014) Potential applicability of persuasive communication to light-glow reduction efforts: a case study of marine turtle conservation. Environ Manage 54:583-595

Kelly I, Leon JX, Gilby BL, Olds AD, Schlacher TA (2017) Marine turtles are not fussy nesters: a novel test of smallscale nest site selection using structure from motion beach terrain information. PeerJ 5:e2770

Klein YL, Osleeb JP, Viola MR (2004) Tourism-generated earnings in the coastal zone: a regional analysis. J Coast Res 20:1080-1088

Krelling AP, Williams AT, Turra A (2017) Differences in perception and reaction of tourist groups to beach marine debris that can influence a loss of tourism revenue in coastal areas. Mar Policy 85:87-99

Laurance WF, Fay JM, Parnell RJ, Sounguet GP, Formia A, Lee ME (2008) Does rainforest logging threaten marine turtles? Oryx 42:1-6

Lawhon B, Newman P, Taff BD, Vaske J, Vagias W, Lawson S, Monz C (2013) Factors influencing behavorial intentions for Leave No Trace behaviors in national parks. J Interpretation Res 18:23-38

Lawhon B, Taff BD, Newman P, Vagias WM, Newton J (2017) Understanding and influencing state park visitors' Leave No Trace behavioral intent. J Interpretation Res 22:53-74

Löhr A, Savelli H, Beunen R, Kalz M, Ragas A, Van Belleghem F (2017) Solutions for global marine litter pollution. Curr Opin Environ Sustain 28:90-99

Lusher AL, Hernandez-Milian G, Berrow S, Rogan E, O'Connor I (2018) Incidence of marine debris in cetaceans stranded and bycaught in Ireland: recent findings and a review of historical knowledge. Environ Pollut 232: $467-476$

Marion JL, Reid SE (2001) Development of the US Leave No Trace program: an historical perspective. In: Usher MB (ed) Enjoyment and understanding of the natural heritage. The Stationery Office, Edinburgh, p 81-92

Mascovich KA (2018) The nesting ecology of sea turtles: managing people, infrastructure, and habitat. MSc thesis, University of Georgia, Athens, GA

Matsuzawa Y, Sato K, Sakamoto W, Bjorndal KA (2002) Seasonal fluctuations in sand temperature: effects on the incubation period and mortality of loggerhead sea turtle (Caretta caretta) pre-emergent hatchlings in Minabe, Japan. Mar Biol 140:639-646

Maurer AS, De Neef E, Stapleton S (2015) Sargassum accumulation may spell trouble for nesting sea turtles. Front Ecol Environ 13:394-395

Mazaris AD, Matsinos YG, Pantis JD (2009) Evaluating the impacts of coastal squeeze on sea turtle nesting. Ocean Coast Manage 52:139-145

McGehee MA (1990) Effects of moisture on eggs and hatch- lings of loggerhead sea turtles (Caretta caretta). Herpetologica 46:251-258

*Mcllgorm A, Campbell HF, Rule MJ (2011) The economic cost and control of marine debris damage in the AsiaPacific region. Ocean Coast Manage 54:643-651

Mosier AE, Witherington BE (2002) Documented effects of coastal armoring structures on sea turtle nesting behavior. In: Mosier A, Foley A, Brost B (eds) Proc 20th Annu Symp Sea Turtle Biol Conserv, 29 Feb-4 Mar, 2000, Orlando, FL. NOAA Tech Memo NMFS-SEFSC-477. National Marine Fisheries Service, St. Petersburg, FL, p 304-306

* Mrosovsky N, Yntema CL (1980) Temperature dependence of sexual differentiation in sea turtles: implications for conservation practices. Biol Conserv 18:271-280

*Murdukhayeva A, August P, Bradley M, LaBash C, Shaw N (2013) Assessment of inundation risk from sea level rise and storm surge in northeastern coastal national parks. J Coast Res 29:1-16

Nelms SE, Duncan EM, Broderick AC, Galloway TS and others (2016) Plastic and marine turtles: a review and call for research. ICES J Mar Sci 73:165-181

Nerem RS, Beckley BD, Fasullo JT, Hamlington BD, Masters D, Mitchum GT (2018) Climate-change-driven accelerated sea-level rise detected in the altimeter era. Proc Natl Acad Sci USA 115:2022-2025

* Neumann JE, Hudgens DE, Herter J, Martinich J (2010) Assessing sea-level rise impacts: a GIS-based framework and application to coastal New Jersey. Coast Manage 38: 433-455

NMFS \& USFWS (US National Marine Fisheries Service \& US Fish and Wildlife Service) (2008) Recovery plan for the Northwest Atlantic population of the loggerhead sea turtle (Caretta caretta), 2nd rev. US National Marine Fisheries Service and US Fish \& Wildlife Service, Silver Spring, MD

* O'Connor JM, Limpus CJ, Hofmeister KM, Allen BL, Burnett SE (2017) Anti-predator meshing may provide greater protection for sea turtle nests than predator removal. PLOS ONE 12:e0171831

* Ockwell D, Whitmarsh L, O'Neill S (2009) Reorienting climate change communication for effective mitigation: forcing people to be green or fostering grass-roots engagement? Sci Commun 30:305-327

Oliver de la Esperanza A, Martínez AA, Tuz MT, Pérez-Collazos E (2017) Are anthropogenic factors affecting nesting habitat of sea turtles? The case of Kanzul Beach, Riviera Maya-Tulum (Mexico). J Coast Conserv 21:85-93

Oosterhuis F, Papyrakis E, Boteler B (2014) Economic instruments and marine litter control. Ocean Coast Manage 102:47-54

\% Owens KA (2018) Using experiential marine debris education to make an impact: collecting debris, informing policy makers, and influencing students. Mar Pollut Bull 127: 804-810

Phillips MR, Jones AL (2006) Erosion and tourism infrastructure in the coastal zone: problems, consequences and management. Tour Manage 27:517-524

* Pike DA, Roznik EA, Bell IP (2015) Nest inundation from sea-level rise threatens sea turtle population viability. $R$ Soc Open Sci 2:150127

Pilkey OH, Wright HL (1988) Seawalls versus beaches. J Coast Res Spec Issue 4:41-64

Ranasinghe R (2016) Assessing climate change impacts on open sandy coasts: a review. Earth Sci Rev 160:320-332

* Rangel-Buitrago N, Williams AT, Anfuso G (2018) Hard protection structures as a principal coastal erosion manage- 
ment strategy along the Caribbean coast of Colombia. A chronicle of pitfalls. Ocean Coast Manage 156:58-75

Richards ZT, Beger M (2011) A quantification of the standing stock of macro-debris in Majuro lagoon and its effect on hard coral communities. Mar Pollut Bull 62:1693-1701

Rizkalla CE, Savage A (2011) Impact of seawalls on loggerhead sea turtle (Caretta caretta) nesting and hatching success. J Coast Res 27:166-173

Roberts CM, Hawkins JP (1999) Extinction risk in the sea. Trends Ecol Evol 14:241-246

Ruggiero P, Komar PD, McDougal WG, Marra JJ, Beach RA (2001) Wave runup, extreme water levels and the erosion of properties backing beaches. J Coast Res 17:407-419

Schlacher TA, Schoeman DS, Dugan JE, Lastra M, Jones AR, Scapini F, McLachlan A (2008) Sandy beach ecosystems: key features, sampling issues, management challenges and climate change impacts. Mar Ecol 29:70-90

Sheavly SB, Register KM (2007) Marine debris \& plastics: environmental concerns, sources, impacts and solutions. J Polym Environ 15:301-305

Silva E, Marco A, da Graça J, Pérez H and others (2017) Light pollution affects nesting behavior of loggerhead turtles and predation risk of nests and hatchlings. J Photochem Photobiol B 173:240-249

Stelfox M, Hudgins J, Sweet M (2016) A review of ghost gear entanglement amongst marine mammals, reptiles and elasmobranchs. Mar Pollut Bull 111:6-17

Stewart KM, Norton TM, Tackes DS, Mitchell MA (2016) Leatherback ecotourism development, implementation, and outcome assessment in St. Kitts, West Indies. Chelonian Conserv Biol 15:197-205

Stucker JH, Cuthbert FJ, Winn B, Noel BL and others (2010) Distribution of non-breeding Great Lakes piping plovers (Charadrius melodus) along Atlantic and Gulf of Mexico coastlines: ten years of band sightings. Waterbirds 33: 22-32

Taff BD, Newman P, Vagias WM, Lawhon B (2014) Comparing day-users' and overnight visitors' attitudes concerning Leave No Trace. J Outdoor Recreat Educ Leadersh 6: 133-146

Thiault L, Kernaleguen L, Osenberg CW, Claudet J (2017) Progressive-change BACIPS: a flexible approach for environmental impact assessment. Methods Ecol Evol 8: 288-296

Tisdell CA, Wilson C (2002) Ecotourism for the survival of sea turtles and other wildlife. Biodivers Conserv 11: 1521-1538

Tisdell CA, Wilson C (2005) Perceived impacts of ecotourism on environmental learning and conservation: turtle watching as a case study. Environ Dev Sustain 7:291-302

Torres A, Palacín C, Seoane J, Alonso JC (2011) Assessing the effects of a highway on a threatened species using before-during-after and before-during-after-controlimpact designs. Biol Conserv 144:2223-2232

Editorial responsibility: Matthew Godfrey, Beaufort, North Carolina, USA
Triessnig P, Roetzer A, Stachowitsch M (2012) Beach condition and marine debris: new hurdles for sea turtle hatchling survival. Chelonian Conserv Biol 11:68-77

Tucker AD, Condran S, Mota MJ, Grimes J, Hays AW, Clark P (2005) Sea turtle monitoring, nest evaluation \& protection measures for the City of Sarasota: year two post-construction - new pass inlet channel maintenance dredging with beach sand placement on Lido Key 2005. Tech Rep No. 1060. Mote Marine Laboratory, Sarasota, FL

Tucker AD, Hays AW, Beggs J, Welsh R and others (2006) Sea turtle monitoring, nest evaluation, and protection measures for Lido Key 2006. Tech Rep No. 1122. Mote Marine Laboratory, Sarasota, FL

Tucker AD, Welsh R, Mazzarella K, Garrett K, Hirsch S (2009) Sea turtle monitoring, nest evaluation, and protection measures for Casey Key 2009. Tech Rep No. 1434. Mote Marine Laboratory, Sarasota, FL

Turner JM (2002) From woodcraft to Leave No Trace: wilderness, consumerism, and environmentalism in twentiethcentury America. Environ Hist 7:462-484

Wallace BP, Sotherland PR, Spotila JR, Reina RD, Franks BF, Paladino FV (2004) Biotic and abiotic factors affect the nest environment of embryonic leatherback turtles, Dermochelys coriacea. Physiol Biochem Zool 77:423-432

Walton County Board of County Commissioners (2018) WAL Ord. 22\$22-54: regulation of use and conduct on the beach and water bodies. Walton Code of Ordinances, DeFuniak Springs, FL

Ware M, Fuentes MMPB (2018) A comparison of methods used to monitor groundwater inundation of sea turtle nests. J Exp Mar Biol Ecol 503:1-7

Ware M, Long JW, Fuentes MMPB (2019) Using wave runup modeling to inform coastal species management: an example application for sea turtle nest relocation. Ocean Coast Manage 173:17-25

W Weishampel ZA, Cheng WH, Weishampel JF (2016) Sea turtle nesting patterns in Florida vis-à-vis satellite-derived measures of artificial lighting. Remote Sens Ecol Conserv 2:59-72

* Whitmore CP, Dutton PH (1985) Infertility, embryonic mortality and nest-site selection in leatherback and green sea turtles in Suriname. Biol Conserv 34:251-272

*Williams AT, Rangel-Buitrago NG, Anfuso G, Cervantes O, Botero CM (2016) Litter impacts on scenery and tourism on the Colombian north Caribbean coast. Tour Manage 55:209-224

Witherington BE (1992) Behavioral responses of nesting sea turtles to artificial lighting. Herpetologica 48:31-39

Witherington BE, Hirama S, Mosier A (2011) Sea turtle responses to barriers on their nesting beach. J Exp Mar Biol Ecol 401:1-6

Zeppel H (2008) Education and conservation benefits of marine wildlife tours: developing free-choice learning experiences. J Environ Educ 39:3-18

Submitted: March 15, 2019; Accepted: December 10, 2019 Proofs received from author(s): February 4, 2020 